\title{
O gênero Encyclia (Orchidaceae) no Distrito Federal, Goiás e Tocantins
}

\author{
The genus Encyclia (Orchidaceae) in the Distrito Federal, Goiás and Tocantins
}

\author{
Thiago E.C. Meneguzzo ${ }^{1,4}$, Luciano B. Bianchetti ${ }^{2}$ \& Carolyn E.B. Proença ${ }^{3}$
}

\begin{abstract}
Resumo
São reconhecidas seis espécies do gênero Encyclia, Orchidaceae, no Distrito Federal, Goiás e Tocantins (Brasil), a saber: E. argentinensis, E. chapadensis, E. cyperifolia, E. gonzalezii, E. linearifolioides e E. osmantha. Todos os espécimes foram registrados no bioma Cerrado. Um total de 42 nomes foram estudados. Duas sinonimizações, quatro lectótipos e dois epítipos são propostos. Um nome é apresentado como inválido, quatro como supérfluos e quatro como "nomen nudum". Treze nomes, incluídos em listagens anteriores para a área em questão, foram excluídos do tratamento por falta de material testemunho ou outro tipo de evidência e três são registrados como de possível ocorrência.
\end{abstract}

Palavras-chave: bioma Cerrado, flora, Neotrópico, Orchidaceae, taxonomia.

\begin{abstract}
Six species of the genus Encyclia are accepted in the Distrito Federal, Goiás and Tocantins (Brazil): E. argentinensis, E. chapadensis, E. cyperifolia, E. gonzalezii, E. linearifolioides and E. osmantha. All the specimens were collected in the Cerrado biome. In total 42 names were analyzed. Two synonyms, four lectotypes and two epitypes are proposed. A name is presented as invalid, four are superfluous and four are "nomen nudum". Thirteen names are excluded from treatment and twenty-one are presented as invalid and three are registered as a possible occurrence.
\end{abstract}

Key-words: Cerrado biome, flora, Neotropic, Orchidaceae, taxonomy.

\section{Introdução}

O gênero Encyclia Hook. é neotropical e exclusivamente americano, pertencente à família Orchidaceae, subfamília Epidendroideae Lindl., tribo Epidendreae Kunth e subtribo Laeliinae Benth. Possui cerca de 120 espécies distribuídas desde a Flórida, México até sul do Brasil e nordeste da Argentina (van den Berg et al. 2005). No Brasil ocorrem 54 espécies (Barros et al. 2010).

Proposto por Hooker (1828) para abrigar parte das espécies de Epidendrum L., Encyclia se caracterizava pelo caule intumescido em pseudobulbo, coluna que era envolvida pelos lobos laterais, assim como por esta ser totalmente livre do labelo. No entanto, o novo gênero não teve aceitação integral por parte de botânicos da época (e.g. Lindley 1853) e de outros posteriores (e.g. Ames et al. 1936), que continuaram defendendo o posicionamento do grupo apenas como uma seção de Epidendrum. Coube a Schlechter (1914) restabelecê-lo, quando propôs inúmeras combinações. Dressler (1961) apoiou a decisão de Schlechter, porém recircunscreveu Encyclia em um sentido mais amplo, propondo a seção Osmophyta (Lindl.) Dressler para Encyclia, compreendendo assim parte das espécies de Epidendrum que continham pseudobulbos, flores em sua maioria não ressupinadas, labelo parcialmente adnato a coluna, rostelo não partido e cápsula alada. Segundo o autor, tais procedimentos foram necessários para deixar Epidendrum como uma entidade homogênea. Mais tarde, Higgins (1997) transferiu as espécies de tal seção de Encyclia para o restabelecido gênero Prosthechea Knowles \& Westec., baseado em análise de filogenética morfológica. Assim, a circunscrição do gênero Encyclia aqui aceita é a

\footnotetext{
Instituto de Pesquisas Jardim Botânico do Rio de Janeiro, R. Pacheco Leão 915, 22460-030, Rio de Janeiro, RJ, Brasil.

${ }^{2}$ Empresa Brasileira de Agricultura e Pecuária, Recursos Genéticos e Biotecnologia, Brasília, DF, Brasil.

${ }^{3}$ Universidade de Brasília, Depto. Botânica, C.P. 4457, 70919-970, Brasília, DF, Brasil.

${ }^{4}$ Autor para correspondência: meneguzzotec@gmail.com
} 
mais restrita, concordando com as propostas de Hooker e Schlechter, sendo este comprovadamente monofilético com base em análises anatômicas e moleculares, desde que se mantenha Epidendrum e Prosthechea a parte, como tratado por van den Berg et al. $(2005,2009)$.

Não há um trabalho de revisão taxonômica para o gênero como um todo e as publicações existentes se resumem basicamente a floras regionais (Dressler \& Pollard 1974; Sauleda \& Adans 1983; Christenson \& Carnevali 1988), sinopses, listas de espécies e iconografias (Hoehne 1952; Pabst \& Dungs 1975, 1977; Castro Neto 1998a, 1998b, 2006; Campacci 2003; Castro Neto \& Campacci 2000; Withner 1996, 1998, 2000), além da descrição de dezenas de novas espécies e alguns híbridos naturais. Para o Brasil, o tratamento mais completo no qual constam descrições, chaves e ilustrações, foi feito por Barbosa Rodrigues (1877, 1882 e 1891) e Cogniaux (1898). Concluise, portanto, que a revisão do gênero faz-se necessária, uma vez que hoje, os trabalhos de Barbosa Rodrigues e Cogniaux se mostram defasados, conflitantes e carentes de informações, diante da realidade presente.

Considerando a ampla área de dispersão do gênero Encyclia e o grande número de espécies envolvidas, foi definida como área para estudo taxonômico as espécies ocorrentes no Distrito Federal e Estados de Goiás e Tocantins. Para essas foram realizadas descrições, sinonimizações, análise de espécimes e tipos nomenclaturais, e quando necessário, a análise e determinação de tipos nomenclaturais. Foram excluídos nomes que não correspondessem aos táxons examinados por erros de identificação, histórico taxonômico confuso ou que constassem da literatura, e que também não estivessem atrelados à existência de material testemunho depositado em herbário.

\section{Materiais e Métodos}

Área de estudo

As unidades federativas de Goiás e Distrito Federal pertencem à região Centro-Oeste, já Tocantins à região Norte do Brasil. O Estado de Goiás possui uma área de $340.086 \mathrm{~km}^{2}$; inserido, predominantemente, no bioma Cerrado com pequenos encraves de Floresta Atlântica ao sudoeste; apresenta altitudes em geral entre 500-1000 m. O Distrito Federal possui uma área de $5.748 \mathrm{~km}^{2}$, totalmente inserido no bioma Cerrado, apresentando amplitude altitudinal geralmente entre 700-1100 m. O Tocantins possui área de $277.620 \mathrm{~km}^{2}$; inserido, predominantemente, no bioma Cerrado com áreas pertencentes ao bioma Amazônico ao norte e noroeste; apresenta amplitude altitudinal em torno de 200-800 m (Silva et al. 2008).

\section{Procedimentos}

Foram examinados materiais depositados nos herbários CEN, G, HB, HEPH, HTO, HUEFS, IBGE, RB, SP, UB, UC, UFG, acrônimos segundo Thiers (2010).

Informações ecológicas, morfológicas, de freqüência relativa e de distribuição foram retiradas das etiquetas dos materiais de herbário examinados. Informações adicionais sobre os táxons ocorrentes no Distrito Federal provêm de Batista \& Bianchetti (2003). A terminologia empregada para identificar as fitofisionomias do bioma Cerrado segue a proposta de Ribeiro \& Walter (2008).

A identificação de material foi realizada por meio de comparação com exsicatas previamente identificadas por especialistas e por trabalhos de Cogniaux (1898), Pabst \& Dungs $(1975,1977)$, Castro Neto (2006) e Castro Neto \& Campacci (2006). Todos os protólogos e a maioria dos tipos nomenclaturais foram consultados e analisados.

Dados relativos à distribuição dos táxons estudados foram obtidos somente pelo levantamento dos tipos nomenclaturais e de materiais depositados em herbário, aqui mencionados na parte de material adicional.

Utilizou-se a terminologia morfológica proposta por Weberling (1989), Dressler (1990), Szlachetko \& Margońska (2002) e Stern (2004) para descrição dos táxons.

\section{Resultados e Discussão}

Tratamento taxonômico

Encyclia Hook., Bot. Mag. 55: t. 2831. 1828. Tipo: Encyclia viridiflora Hook., Bot. Mag. 55: t. 2831. 1838. Epidendrum viridiflorum (Hook.) Lindl., Edwards's Bot. Reg. 28 (misc.): 30. 1842.

Doxosma Raf., Fl. Tell. 4: 9. 1838. Tipo: Epidendrum gracile Lindl., Edwards's Bot. Reg. 21: t. 1765. 1835. Doxosma gracilis (Lindl.) Raf., Fl. Tell. 4: 9. 1838. Encyclia gracilis (Lindl.) Schltr., Orchideen (Schlecter): 209. 1914. 
Exophya Raf., Fl. Tell. 3: 63. 1837. Tipo: Encyclia patens Hook., Bot. Mag. 57: t. 3013. 1830. Exophya fuscata Raf., Fl. Tell. 3: 63. 1837.

Sulpitia Raf., Fl. Tell. 4: 37. 1838. Tipo: Epidendrum odoratissimum Lindl., Edwards's Bot. Reg. 17: t. 1415. 1831. Sulpitia odorata Raf., Fl. Tell. 4: 37. 1838. Encyclia odoratissima (Lindl.) Schltr., Orchideen (Schlechter): 210. 1914.

Ervas epífitas ou rupícolas, simpodial. Raiz branca e crassa. Rizoma freqüentemente inconspícuo, coberto por brácteas membranáceas. Pseudobulbo ovóide, piriforme ou esférico, heteroblástico, bainhas persistentes durante floração. Folhas terminais ao pseudobulbo; 1-3(-4), presente durante a floração; sésseis; linear ou lanceolada; margem inteira; plana ou canaliculada; coriácea ou carnosa. Inflorescência terminal ao pseudobulbo; racemo simples ou duplo; desprovida de espata; 1-50 flores; geralmente maior que as folhas. Flores ressupinadas, dialissépalas, dialipétalas, pediceladas, freqüentemente odorífera. Sépalas lanceoladas, elípticas ou espatuladas, base atenuada; dorsal simétrica, laterais simétricas ou assimétricas. Pétalas espatuladas ou lanceoladas. Labelo livre da coluna, base não ungüiculada, calo longitudinal formado por duas lamelas, cimbiforme; trilobado, lobos laterais ovais, oblongos ou triangulares; lobo mediano orbicular, elíptico ou obovado, ápice inteiro, agudo ou emarginado, com istmo, raríssimo séssil. Coluna semi-clavada, geralmente com duas asas adjacentes ao estigma; estigma oval a oboval, côncavo, viscoso, rostelo curvado apicalmente, antera incumbente, 4 políneas, em pares, lateralmente compressas, elípticas, ceróides, iguais, paralelas, amarelas, caudícula linear, granular, viscídio ausente. Cápsula, fusiforme; lisa, verrucosa ou espiculada; 6-costada.

\section{Chave para as espécies de Encyclia no Distrito Federal, Goiás e Tocantins}

1. Coluna sem asas.

2. Pseudobulbo esférico, 1,2-1,4 cm diâm.; folha canaliculada; lobos laterais do labelo triangulares 3. E. cyperifolia

2'. Pseudobulbo ovóide, 1,5-3 × 1-1,5 cm diâm.; folha plana; lobos laterais do labelo ovados. 5. E. linearifolioides

1. Coluna com asas.

3. Ápice do calo do labelo inteiro.

4. Lobos laterais do labelo oblongos

2. E. chapadensis

4'. Lobos laterais do labelo elípticos

6. E. osmantha

3'. Ápice do calo do labelo trífido.

5. Sépala dorsal 1,7-1,9 cm comp.; lobo medial do labelo elíptico, oval ou oboval, lobo lateral oblongo 1. E. argentinensis

5'. Sépala dorsal 1,3-1,5 cm comp.; lobo medial do labelo orbicular, lobo lateral ovado

4. E. gonzalezii

1. Encyclia argentinensis (Speg.) Hoehne, Arq. Bot. Estado São Paulo 2(6): 150. 1952. Epidendrum argentinense Speg., Anales Mus. Nac. Hist. Nat. Buenos Aires 28: 135. 1916. Tipo: ARGENTINA. MISIONES: alredores de San Pedro, C.L. Spegazzini (holótipo não localizado; lectótipo, aqui designado, ilustração publicada em Spegazzini (1916, p. 136)). Figs. 1a, 2a

Encyclia saltensis Hoehne, Arq. Bot. Estado São Paulo 1(1): 19. 1938. Tipo: ARGENTINA. SALTA: Orán, Urundel, Montealto, 6.XII.1913, fl., D. Rodriguez 1164 (holótipo, LP1164 ["Museu de La Plata"] não localizado; lectótipo, aqui designado: SP!, foto do isolectótipo AMES!).
Encyclia burle-marxii Pabst, Bradea 2(48): 313. 1979. Tipo: BRASIL. ESPÍRITO SANTO: Baixo Guandu, 5.XI.1978, fl., R. Burle Marx s.n. (holótipo: HB!).

Encyclia goyazensis L.C.Menezes ex Fowlie, Orchid Digest 55(2): 94. [Apr.-May-June] 1991. Encyclia goyazensis L.C.Menezes, Bol. CAOB 3(3): 14. [Maio/Agosto] 1991. Tipo: BRASIL. GOIÁS: "Marzagão e Caldas Novas", 26.X.1990, fl., L.C. Menezes UB7 (holótipo: UB!). nom. superfl.

Encyclia schmidtii L.C.Menezes ex Fowlie, Orchid Digest 55(2): 92. 1991. Tipo: BRASIL. MATO GROSSO: Sorriso, Chapada dos Parecis, 

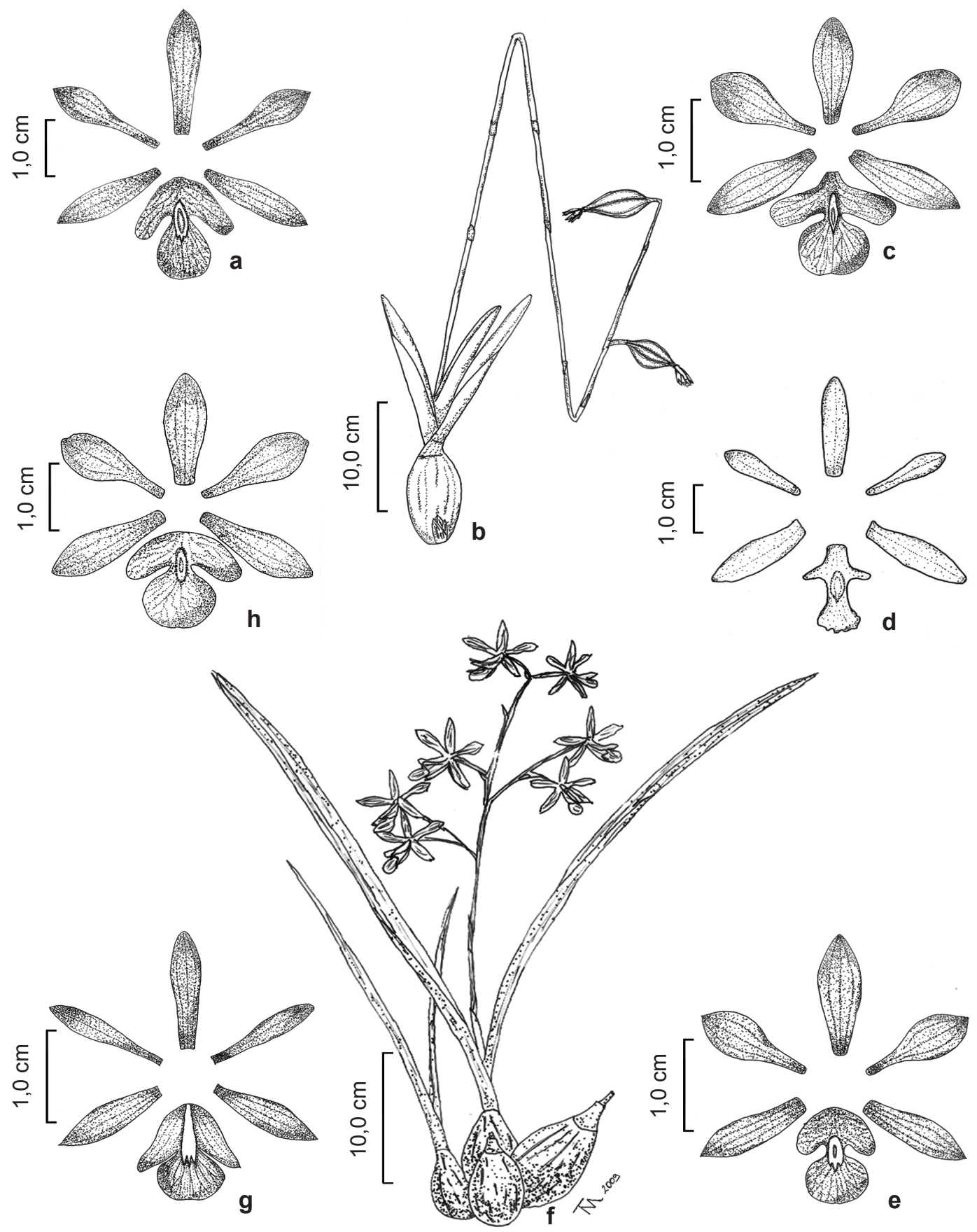

Figura 1 - a. Encyclia argentinensis (Heringer et al. 5797) - a. perianto distendido. b-c. E. chapadensis - b. habito com fruto (Irwin et al. 32960). c. perianto distendido (Menezes UB16 - holótipo). d. E. cyperifolia (Serafim Sobrinho sub Meneguzzo 231) - d. perianto distendido. e. E. gonzalezii (Menezes UB1 - holótipo) - e. perianto distendido. f-g. E. linearifolioides (Salles et al. 3815) - f. habito com inflorescência; g. perianto distendido (Salles et al. 3815). h. E. osmantha (Mendonça et al. 4996) - h. perianto distendido. Por T.E.C. Meneguzzo

Figure 1 - a. Encyclia argentinensis (Heringer et al. 5797) - a. dissected perianth. b-c. E. chapadensis - b. habit and fruit (Irwin et al. 32960). c. dissected perianth (Menezes UB16 - holótipo). d. E. cyperifolia (Serafim Sobrinho sub Meneguzzo 231) - d. dissected perianth. e. E. gonzalezii (Menezes UB1 - holótipo) - e. dissected perianth. f-g. E. linearifolioides (Salles et al. 3815) - f. habit and inflorescence; g. dissected perianth (Salles et al. 3815). h. E. osmantha (Mendonça et al. 4996) - h. dissected perianth. By T.E.C. Meneguzzo 
s.d., estéril, A. Schmidt sub L.C. Menezes UB6 (holótipo: UB!; epítipo, aqui designado: fotografia publicada no inferior e a direita em Menezes (1991a, p. 93)).

Encyclia piracanjubensis L.C.Menezes, Bol. CAOB 3(3): 16, 1991. Tipo: BRASIL. GOIÁS: Piracanjuba, 9.XI.1990, fl., L.C. Menezes, H.A. Lima \& G. Salu UB10 (holótipo: UB!).

Encyclia santos-dumontii L.C.Menezes, Bol. CAOB 4(1): 12. 1992. Tipo: BRASIL. DISTRITO FEDERAL: $6^{\circ}$ Comando Aéreo, 19.XI.1991, fl., L.C. Menezes UB29 (holótipo:UB!), nov. syn.

Encyclia pedra-azulensis L.C.Menezes, Orchid Digest 56(3): 148. 1992. Tipo: BRASIL. ESPÍRITO SANTO: Pedra Azul, floração em cultivo em XI.1991, B. Damião sub L.C. Menezes UB28 (holótipo: UB, não localizado; lectótipo, aqui designado: fotografia publicada à direita na parte inferior na página em Menezes (1992b, p.149)).

Encyclia perazolliana J.Gonzalez, Bol. CAOB 4(1): 21. 1992. Tipo: não designado, nom. inval.

Encyclia meneziana J.Gonzalez, Bol. CAOB 4(1): 39. 1992. Tipo: BRASIL. GOIÁS: Goiandira, florescimento em cultivo em XI.1989, J. Gonzalez Raposo sub L.C. Menezes UB27 (holótipo: UB!).

Encyclia clovesiana L.C.Menezes \& V.P.Castro, Orquidario 21(1): 19. 2007. Tipo: BRASIL. RONDÔNIA: Alto Alegre dos Parecis, floração em cultivo XI.2006, fl., C. Araujo sub L.C. Menezes UB 99 (holótipo: UB!), nov. syn.

Epífita. Raiz 0,1-0,2 cm diâm. Rizoma 1-2 $\times 0,6-0,8 \mathrm{~cm}$. Pseudobulbo estreito-ovóide, verde, marrom a roxo-escuro, $3,5-5 \times 0,4-2 \mathrm{~cm}$. Folha $1-2$, linear, plana, verde, coriácea, $29-41 \times 0,6-1,8$ $\mathrm{cm}$. Inflorescência duplo racemosa, (3-)8-38 flores, $30-57 \mathrm{~cm}$; pedúnculo $24-39 \mathrm{~cm}$; raque 19-27 cm. Flor com ovário pedicelado verde, $2-2,5 \mathrm{~cm}$. Sépalas lanceoladas, verde a marrom, $1,7-1,9 \times 0,3-0,5 \mathrm{~cm}$. Pétalas espatuladas, verde a marrom, 1,5-1,7 × 0,4-0,5 cm. Labelo 1,7-2,0 $\times 1,7-1,9 \mathrm{~cm}$; lobos laterais oblongos, bege a verde, $0,7-1,1 \times 0,3-0,4 \mathrm{~cm}$; lobo medial elíptico, obovado ou oval, ápice arredondado, truncado ou obtuso, bege, centro com nervuras rosas ou não, $0,8-1 \times 0,8-0,9 \mathrm{~cm}$; calo com ápice trífido, $0,7 \times$ $0,3 \mathrm{~cm}$. Coluna com asas, bege a verde, $1 \times 0,4 \mathrm{~cm}$; antera bege a roxa. Cápsula verrucosa, $0,4-0,6 \times$ $0,4-0,5 \mathrm{~cm}$.

Material examinado: BRASIL. DISTRITO FEDERAL: Bacia do Rio São Bartolomeu, XI.1980, fl., E.P. Heringer et al. 5797 (IBGE). GOIÁS: Alexania, 27.X.1990, fl., J.A.N. Batista (CEN 26611). Ipameri, bacia de inundação do AHE Corumbá, 4.XII.2003, fl., T.B. Cavalcanti et al. 2121 (CEN); Fazenda Fundão, próximo ao córrego Jucubeiro, 18.X.1994, fl., H.G.P. Santos et al. 52604 (CEN); Fazenda Santo Antônio do Fundão, 1.XI.2003, fl., T.B. Cavalcanti et al. 1403 (CEN). Iporá, Fazenda Jacuba, 11.X.2008, fl., T.E.C. Meneguzzo et al. 17 (UB); idem, 11.X.2008, fl., T.E.C. Meneguzzo et al. 19 (UB); idem, 11.X.2008, fl., T.E.C. Meneguzzo et al. 16 (UB). Luziânia, Fazenda Tamburil, 12.XI.2002, fl., G. PereiraSilva et al. 7055 (CEN). Morrinhos, estrada Morrinhos p/ Caldas Novas, córrego Samambaia, fl., J.A. Rizzo \& A. Barbosa 5598 (UFG). Rio São Marcos, 20.X.1963, fl., D. Márcia (HB 88617).

Material adicional examinado: ARGENTINA. SALTA: Orán, XI.1974, fl., V. Maruñak 634 (HB). BRASIL. MATO GROSSO: Cocalinho, XII.2003, fl., G. PereiraSilva \& R.C. Oliveira 3717 (CEN). MATO GROSSO DO SUL: Ivinhema, rio Vitória, 25.X.2009, fl., C.P. Ferreira s.n. (UB). MINAS GERAIS: Patrocínio, 5.IX.1991, fl., I. Valente 21 (HEPH). SÃO PAULO: Taquaritinga, 2.II.1972, fl., A. Seidel 1022 (HB).

Espécie de ampla distribuição, ocorrendo no norte da Argentina (província de Misiones e Salta) e Brasil (Rondônia, Mato Grosso, Mato Grosso do Sul, Goiás, Distrito Federal, Minas Gerais, Espírito Santo e São Paulo). Provavelmente ocorre também no Estado do Paraná (Brasil), no Paraguai, e na Bolívia, por serem áreas limítrofes à distribuição atualmente conhecida.

No Cerrado brasileiro é registrado em borda de mata de galeria e matas secas, sendo nesse último preferencialmente em grotas ou lugares que apresentem umidade. Floresce predominantemente no final do período seco e início do chuvoso, de agosto a novembro.

Em Iporá, Goiás, foram registrados crescendo nos forófitos Clusia sellowiana Schltdl. (Clusiaceae) e Hirtella gracilipes (Hook.f.) Prance (Chrysobalanaceae).

Passível de confusão com Encyclia osmantha (Barb.Rodr.) Schltr., na qual se diferencia por materiais herborizados que geralmente apresentam a parte vegetativa marrom muito escura em $E$. argentinensis e marrom claro em E. osmantha. Também pelos pseudobulbos, folhas, pétalas e sépalas proporcionalmente mais estreitos em $E$. argentinensis em relação a E. osmantha. Labelo com calo muito proeminente e ápice trífido, forma do lobo medial bem variável (elíptico, oval ou oboval) em E. argentinensis em contraste com calo pouco proeminente com ápice inteiro e forma do lobo medial transverso-elíptico em E. osmantha.

Foram realizadas consultas aos herbários argentinos BA, BAA, BAB, BAF e LP com o 
propósito de localizar os holótipos de Encyclia argentinensis e Encyclia saltensis Hoehne, porém tais materiais não foram encontrados. Posto isso, a ilustração presente no protólogo é indicada como lectótipo do primeiro nome. Da mesma forma, o lectótipo de E. saltensis é selecionado dentre os isótipos encontrados.

Devido à variabilidade morfológica observada no labelo, a espécie Encyclia argentinensis foi descrita como muitos táxons diferentes. Primão (1997) com base em exemplares de Encyclia coletados e cultivados na cidade de Casa Branca, Estado de São Paulo, descreveu dezessete diferentes espécies, cada uma baseada em um único espécime, a saber: E. alta Primão, E. aryana Primão, E. casabranquensis Primão, E. ceropiophila Primão, E. cerradiphytica Primão, E. claudiana Primão, E. euglossa Primão, E. feijoana Primão, E. lanceolata Primão, E. limae Primão, E. magellanica Primão, E. odorifera Primão, E. oliveirana Primão, E. peresiana Primão, E. relicta Primão, E. rivulariana Primão e E. tortilis Primão. Tal autor sustenta sua posição calcada na hipótese de isolamento reprodutivo dos espécimes além das diferenças morfológicas apresentadas. Quanto ao isolamento reprodutivo, Primão (1997) não apresenta provas de tal evidência, uma vez que não foram apresentados estudos ou resultados que pudessem corroborar tal afirmação. Acreditamos que exista maior probabilidade da ocorrência de eventos contrários à hipótese formulada por Primão, uma vez que os espécimes são simpátricos e apresentam período de floração próximos, se não iguais, ou seja, duas condições (geográfica e temporal) necessárias para que ocorra a polinização entre indivíduos diferentes, caso não hajam outras barreiras que impeçam o processo. A variação morfológica observada nos espécimes pode ser considerada natural dentro de populações panmíticas, e se enquadram dentro dos padrões fenotípicos aqui aceitos para E. argentinensis. Além disso, todos os nomes atribuídos por Primão (1997) são considerados inválidos, segundo os artigos 36.1 e 37.1 do Código Internacional de Nomenclatura Botânica (McNeil et al. 2006), por não apresentar diagnose latina e por não ter sido designado um tipo nomenclatural. Portanto, todas as espécies descritas por tal autor são aqui indicadas inválidas e aqui pela primeira vez incluídas na sinonímia de E. argentinensis.
Com exceção dos sinônimos novos aqui indicados e da sinonimização de Encyclia saltensis (realizado por Hoehne 1952) os demais sinônimos foram aparentemente propostos pela primeira vez por Castro Neto \& Campacci (2000), apesar dos mesmos não apresentarem designação explícita como recomendada pelo artigo 50A.1 (McNeil et al. 2006).

Do mesmo modo, as características morfológicas observadas em Encyclia santosdumontii L.C.Menezes, E. clovesiana L.C.Menezes \& V.P.Castro e pela primeira vez aqui citada "E. euosma var. matogrossensis Brade" não permitem a distinção em diferentes entidades taxonômicas, pois se enquadram perfeitamente no conceito morfológico de E. argentinensis aceito por nós, e por esse motivo, as são também aqui sinonimizadas. Ressalta-se que "Encyclia euosma var. matogrossensis" nunca foi descrita ou publicada, mesmo que dois materiais tenham sido designados por A.C. Brade e depositados no herbário RB (flor provinda de coleta de 1938 sem local específico do Mato Grosso, com florescimento em cultivo em 1941, sem número de coletor).

Duas espécies descritas por L.C. Menezes foram publicadas em um artigo de autoria de J.A. Fowlie (1991), e por isso freqüentemente esses táxons recebem de maneira incorreta a citação de autoria. Assim sendo devem ser citados Encyclia schmidtii L.C.Menezes ex Fowlie e E. goyazensis L.C.Menezes ex Fowlie e não como "E. schmidtii L.C.Menezes" e "E. goyazensis L.C.Menezes", respectivamente. Encyclia goyazensis L.C.Menezes é um nome supérfluo por ter sido publicado posteriormente a E. goyazensis L.C.Menezes ex Fowlie, tento inclusive o mesmo tipo nomenclatural indicado. O local de coleta do holótipo de $E$. goyazensis L.C.Menezes ex Fowlie é impreciso já que são indicadas duas cidades no estado de Goiás, a saber: Marzagão e Caldas Novas.

O epítipo para E. schmidtii foi determinado com base em fotografia da flor dissecada no protólogo, uma vez que o holótipo não contém flores. O lectótipo para Encyclia pedra-azulensis L.C.Menezes é aqui determinado como a fotografia da flor dissecada apresentada no protólogo, uma vez que o holótipo não foi localizado após intensas buscas no herbário UB.

Encyclia perazolliana J.Gonzalez é nome inválido segundo artigos 37.1 (McNeil et al. 2006) por falta de indicação de tipo nomenclatural. 


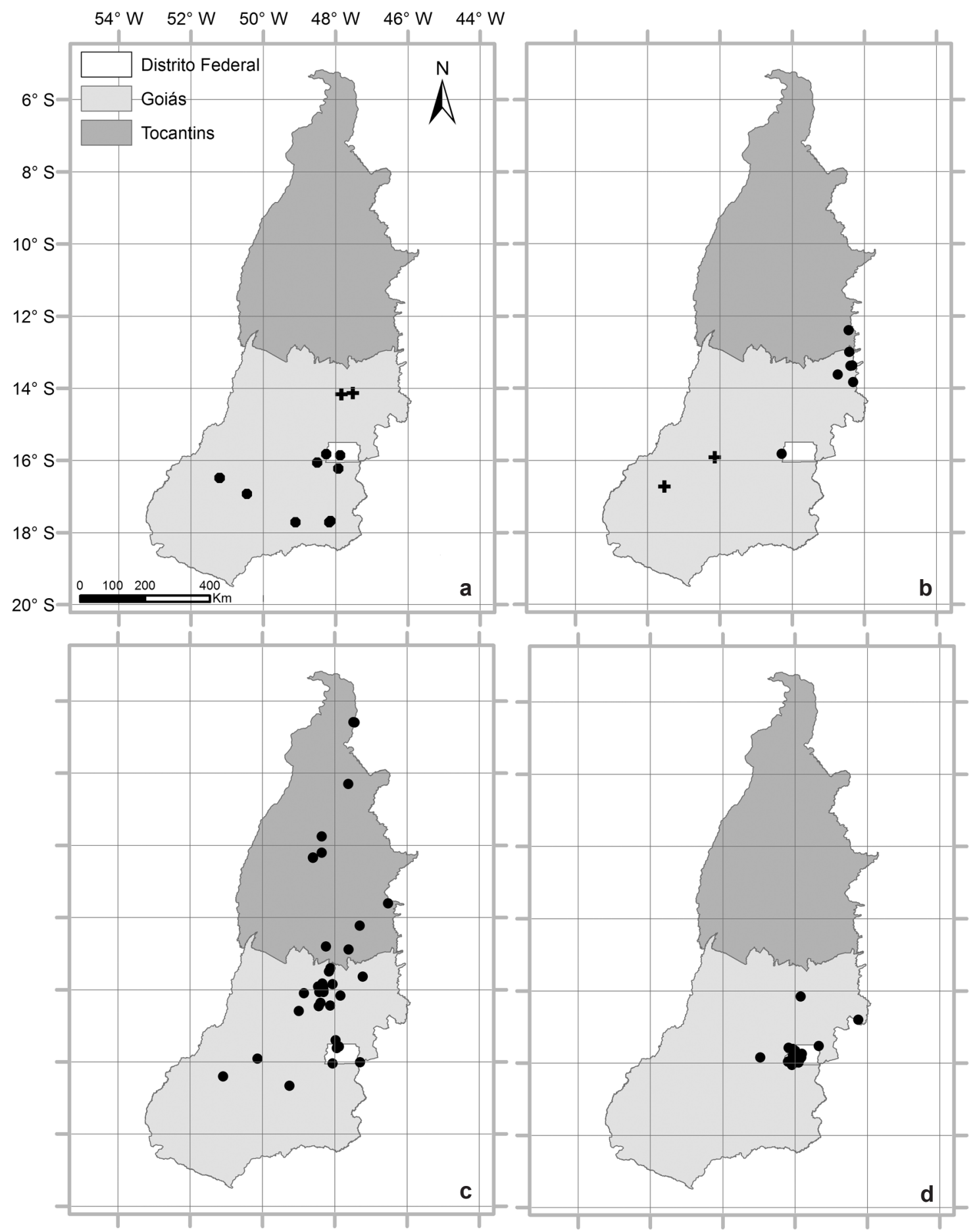

Figura 2 - Distribuição das espécies de Encyclia no Distrito Federal, Goiás e Tocantins. a. E. argentinensis (•), E. chapadensis $(+)$; b. E. cyperifolia $(+)$, E. gonzalezii $(\bullet)$; c. E. linearifolioides $(\bullet)$; d. E. osmantha $(\bullet)$.

Figure 2 - Distribution of Encyclia species in the Distrito Federal, Goiás e Tocantins. a. E. argentinensis $(\bullet)$, E. chapadensis $(\mathbf{+}) ; \mathrm{b}$. E. cyperifolia $(\mathbf{+})$, E. gonzalezii $(\bullet)$; c. E. linearifolioides $(\bullet)$; d. E. osmantha $(\bullet)$. 
No entanto existe um espécime depositado no herbário UB, identificado como tal: BRASIL. GOIÁS: entre Catalão e Goiandira, latifúndio Pari, florescimento em cultivo em XI.1989, E. Perazolli \& J. Gonzalez Raposo sub L.C. Menezes UB30. Apesar do Código permitir que a mesma seja validada por meio de referência direta ao protólogo do nome inválido (ibidem, artigo 32.1.d), e da indicação de um tipo (ibidem, artigo 37.1), foi decidido não fazê-lo. Tal decisão é baseada no fato do espécime-tipo supracitado não possuir flores, pois nada seria acrescentado com essa indicação, uma vez que tal espécime não tem utilidade para discriminação entre diferentes espécies do gênero. Uma opção descartada foi a da indicação do espécime depositado como holótipo e como epítipo a ilustração com uma flor dissecada apresentada no protólogo, já que tal ato é proibido para novas espécies publicadas, ou no caso validadas, a partir de $1^{\circ}$ de janeiro de 2007 (ibidem, artigo 37.4). Também não foram localizados em herbário outros espécimes das localidades tipo como possíveis de serem indicados como holótipos.

2. Encyclia chapadensis L.C.Menezes, Orchid Digest 53(3): 135. 1993. Tipo: BRASIL. GOIÁS: Alto Paraíso, Chapada dos Veadeiros, 22.IX.1991, fl., L.C. Menezes UB16 (holótipo: UB!).

Figs. 1b-c, 2a

Rupícola raro epífita. Raiz $0,1-0,2 \mathrm{~cm}$ de diâmetro. Rizoma $0,5 \times 0,3 \mathrm{~cm}$. Pseudobulbo ovóide a estreito-ovóide, marrom, 4-8 ×1,8-2,5 cm. Folha 2-3, lanceolada a linear, plana, verde a roxo, carnosa, 4-15 × 1-2 cm. Inflorescência racemosa simples, 3-7 flores, 34-92 cm; pedúnculo 27$51 \mathrm{~cm}$; raque $7-29 \mathrm{~cm}$. Flor com ovário pedicelado $1,7-2,1 \mathrm{~cm}$. Sépalas lanceolada, marrom, 2-2,2 $\times$ $0,5-0,7 \mathrm{~cm}$. Pétalas espatuladas, marrom, 2,1-2,3 $\times 0,7-0,9 \mathrm{~cm}$. Labelo $1,8-2 \times 1,9-2,2 \mathrm{~cm}$; lobos laterais oblongos, rosa, $0,8-1,1 \times 0,4-0,6 \mathrm{~cm}$; lobo medial orbicular, rosa, ápice arredondado, 1-1,3 cm diâm.; calo com ápice inteiro, 0,6-0,7 × 0,3 $\mathrm{cm}$. Coluna com asas, bege, $0,7 \times 0,2 \mathrm{~cm}$; antera amarela. Cápsula roxa a marrom, 2-3 × 1-1,5 cm. Material examinado: BRASIL. GOIÁS: Alto Paraíso de Goiás. Chapada dos Veadeiros, 7.X.1972, fl., J.A. Rizzo 8417 (UFG); idem, ca. 13km NW of Veadeiros, 20.X.1965, fl., H.S. Irwin et al. 9340 (HB, UB); idem, ca. $22 \mathrm{~km} \mathrm{~N}$ of Alto do Paraíso, 22.III.1971, fr., H.S. Irwin et al. 32960 (HB, UB), idem, 11.X.2009, fl., T.E.C. Meneguzzo et al. 446 (HUEFS, UB).

Esta espécie, até o momento, foi somente coletada na região da Chapada dos Veadeiros,
Estado de Goiás e, portanto aqui considerada como endêmica. Cresce no bioma Cerrado, em campo rupestre, tipicamente como rupícola em rocha quartzítica, preferencialmente protegida pela sombra propiciada pela vegetação arbóreoarbustiva. Eventualmente cresce com epífita na base do tronco de árvores e arbustos. Floresce no final do período seco e início do período chuvoso, nos meses de setembro e outubro.

Quando comparada com Encyclia argentinensis e E. osmantha destaca-se por apresentar folhas muito crassas e pequenas em relação ao tamanho dos pseudobulbos, características típicas de espécies rupícolas como $E$. seidelii Pabst e E. duveenii Pabst; a inflorescência se mostra três ou mais vezes longa que o tamanho das folhas, pauciflora e os lobos laterais do labelo proporcionalmente muito desenvolvidos para o gênero.

3. Encyclia cyperifolia (C.Schweinf.) Carnevali \& I.Ramírez, Monogr. Syst. Bot. Missouri Bot. Gard. 54: 1257. 1993. Epidendrum microtos var. grandiflorum C.Schweinf., Bot. Mus. Leafl. 11(4): 98. 1943. Encyclia microtos var. grandiflora (C.Schweinf.) Hoehne, Arq. Bot. Estado São Paulo 2(6): 152. 1952. Epidendrum cyperifolium C.Schweinf., Bot. Mus. Leafl. 16(1): 10. 1953. Tipo: PERU. LORETO: Upper Marañon River at mouth of Santiago River at 160 meters altitude, in rain-forest, 15.X.1924, fl., G. Tessmann 4301 (holótipo: $\mathrm{B} \dagger$, fotografia!).

Fig. 1d, 2b

Bletia ensiformis Ruiz \& Pav., Syst. Veg. Fl. Peruv. Chil.: 230. 1798. [Encyclia ensiformis (Ruiz \& Pav.) Mansf. nom. nud. non E. ensiformis (Vell.) Hoehne]. Tipo: PERU. "Habitat in nomoribus Pozuzo supra arbores et saxa versus Cheniço et Tramo tractus", s.d., fl., J.A. Pavón s.n. (holótipo - MA fotografia!).

Epífita. Raiz 0,1-0,2 cm diâm. Rizoma $1 \times$ $0,3 \mathrm{~cm}$. Pseudobulbo esférico, verde, $1,2-1,4 \mathrm{~cm}$ diâm. Folha linear, canaliculada, verde, coriácea, $25-33 \times 0,3 \mathrm{~cm}$. Inflorescência racemosa simples, 5-8 flores, 14-15 cm; pedúnculo 8,5-9,5 cm; raque $3-5 \mathrm{~cm}$. Flor com ovário pedicelado $1,8-2,2$ $\mathrm{cm}$. Sépalas lanceoladas, bege maculada de vermelho, 1,3-1,6 $\times 0,3 \mathrm{~cm}$. Pétalas espatuladas, bege maculada de vermelho, $1,3-1,4 \times 0,2-0,3$ $\mathrm{cm}$. Labelo 1,3-1,6 $\times 0,9-1 \mathrm{~cm}$; lobos laterais triangulares, bege, $0,3 \times 0,2 \mathrm{~cm}$; lobo medial obovado, bege, $0,4-0,6 \times 0,4-0,6 \mathrm{~cm}$; calo com ápice trífido, $0,3 \times 0,1 \mathrm{~cm}$. Coluna sem asas, 
bege, 0,6 × 0,2 cm; antera amarela. Cápsula desconhecida.

Material examinado: BRASIL. GOIÁS: Goiás Velho, 25.VII.2009, fl., J. Serafim Sobrinho sub T.E.C. Meneguzzo 231 (UB). Palestina, 25.VII.2009, fl., J. Serafim Sobrinho sub T.E.C. Meneguzzo 230 (UB).

Em Goiás ocorre no Cerrado, em beira de mata de galeria em transição para cerrado. É considerada rara, sendo que também a freqüência relativa dos espécimes no habitat natural é muito baixa. Floresce durante a estiagem.

Muito distinta das demais espécies por apresentar, conjuntamente, pseudobulbo esférico, folha muito estreita e canaliculada, lobo lateral do labelo triangular e coluna sem asas.

Devido ao fato do holótipo de Encyclia cyperifolia ter sido destruído (com. pess. T.E.C. Meneguzzo com curadoria do herbário B) o parátipo deverá ser designado como lectótipo assim que localizado, uma vez que o autor não informou onde se encontrava depositado. Um provável local de depósito do parátipo seria o herbário F, contudo a referida coleção não foi localizada. "Encyclia ensiformis (Ruiz \& Pav.) Mansf." é um nome nu afixado no holótipo da mesma espécie e também citado por Pabst \& Dungs (1975).

4. Encyclia gonzalezii L.C.Menezes, Orchid Digest 55(1): 24. [Jan.-Feb.-Mar.] 1991. Encyclia gonzalezii L.C.Menezes, Bol. CAOB 3(2): 19. [Janeiro-Abril] 1991, nom. superfl. Tipo: BRASIL. DISTRITO FEDERAL: Divisa com estado de Goiás, Rio Descoberto, florescimento em cultivo VII.1990, N.C. Cazelato sub L.C. Menezes UBI (holótipo: UB!).

Figs. 1e, 2b

Encyclia tocantinensis V.P.Castro \& Campacci, Orquidario 10(3): 74. 1996. Tipo: BRASIL. TOCANTINS: Taguatinga, VIII.1982, florescimento em cultivo X.1983, fl., V.P. Castro Neto s.n. (holótipo: SP!).

Epífita. Raiz 0,1-0,2 cm diâm. Rizoma inconspícuo. Pseudobulbo ovóide, roxo, 2,5-5 × 0,7-1,7 cm. Folha 1-2, linear-lanceolada, plana, roxa, coriácea, $14-39 \times 0,8-1 \mathrm{~cm}$. Inflorescência duplo racemosa, 6-23 flores, 38-58 cm; pedúnculo $10-12 \mathrm{~cm}$; raque $26-56 \mathrm{~cm}$. Flor com ovário pedicelado verde, $2-2,4 \mathrm{~cm}$. Sépalas lanceoladas, verde a marrom, $1,3-1,5 \times 0,3-0,4 \mathrm{~cm}$. Pétalas espatuladas ápice agudo, verde a marrom, 1,4-1,9 $\times 0,3-0,4 \mathrm{~cm}$. Labelo $1,2-1,4 \times 0,8-1 \mathrm{~cm}$; lobos laterais ovado, bege a verde, $0,7-0,8 \times 0,3-0,4$ $\mathrm{cm}$; lobo medial orbicular, ápice arredondado raro obtuso, bege, $0,5-0,7 \times 0,5-0,6 \mathrm{~cm}$ diâm.; calo com ápice trífido, $0,5 \times 0,2 \mathrm{~cm}$. Coluna com asas, bege a verde, $0,6-0,8 \times 0,2 \mathrm{~cm}$; antera bege a amarela. Cápsula verrucosa, 2,5-3,0 × 0,4-0,6 cm.

Material examinado: BRASIL. GOIÁS: Campos Belos, vilarejo de Pouso Alto, fl., 10.X.2010, T.E.C. Meneguzzo et al. 569 (UB). Guaraíta, distrito de Guarani de Goiás, fl., 9.X.2010, T.E.C. Meneguzzo et al. 568 (UB). São Domingos, rio Galheiros, 11.X.2010, fl., fr., T.E.C. Meneguzzo et al. 570 (UB); IX.2004, fl., A.A. Santos et al. 2297 (CEN); idem, s.d., fl., A.A. Santos et al. $410 A$ (CEN, HUEFS, UB); idem, 1.X.2001, fl., A.A. Santos et al. 410 (CEN).

Espécie natural do Distrito Federal (vide comentários abaixo), sudeste do Tocantins e nordeste de Goiás. Ocorre no Cerrado, em mata seca com afloramento calcário, preferencialmente próximo a rios e córregos, ou em grotas e pequenas matas ciliares, podendo neste eventualmente ser rupícola sobre rocha quartzítica. Geralmente cresce protegida do sol em copas de árvores. Floresce no final do período seco e início das chuvas, de setembro a outubro.

Observações dessa espécie tanto em cultivo, quanto em campo, mostram que ao contrário das demais espécies aqui apresentadas, estas sempre mantêm a coloração roxa na parte vegetativa, independente da sua exposição ao sol ou forma de cultivo. Também esta mostra preferência pelo forófito vulgarmente conhecido como "bostade-cabra", Hirtella gracilipes (Hook F.) Prance (Chrysobalanaceae).

Muito próxima de Encyclia argentinensis, mas diferindo da mesma pela parte vegetativa sempre roxa; labelo com lobo lateral ovado, proporcionalmente bem reduzido em relação ao gênero e lobo medial orbicular. Outra característica que a destaca é o ângulo formado entre as sépalas laterais, ca. $180^{\circ}$, o qual é ca. $120^{\circ}$ nas outras espécies da área estudada.

Castro Neto \& Campacci (2000) realizaram a sinonimização de Encyclia tocantinensis V.P.Castro \& Campacci sob E. gonzalezii. Porém, após algum tempo, Campacci (2003) e Castro Neto (2006) desfizeram tal tratamento sem apresentar nenhuma justificativa. Entretanto, segundo análise dos tipos dos dois táxons, concluiu-se que E. tocantinensis deve ser mantida como sinônimo de E. gonzalezii.

Ressalta-se que a fotografia da flor de Encyclia gonzalezii, publicada no protólogo, não pertence à mesma planta depositada como tipo nomenclatural. Tal obra (Menezes, 1991b) declara que a forma dos lobos laterais do labelo 
são "rombóides"; no entanto, em exame minucioso do holótipo, foi verificado que são ovados e idênticos àqueles observados no holótipo de E. tocantinensis. É possível que tal morfologia tenha sido utilizada por Castro Neto \& Campacci (1996) para discriminar E. tocantinensis de E. gonzalezii, apesar de tais autores não o terem mencionado. Entende-se, portanto, que a provável diferenciação na forma dos lobos laterais, neste caso, não justifica a manutenção em dois táxons distintos, já que todos os demais caracteres, tanto vegetativos quanto reprodutivos, condizem com um único táxon.

Acredita-se que o holótipo de Encyclia gonzalezii apresenta informações equivocadas quanto à procedência. A localidade referida no protólogo como "divisa com Estado de Goiás, Rio Descoberto" apresenta vegetação do tipo Cerrado s.s. e entremeada por matas de galeria. As tentativas de recoleta nesse local foram frustradas, sendo que não se encontrou nenhum sinal da existência de tal. Todos os demais espécimes examinados e coletados pelos autores, inclusive o da localidade tipo de E. tocantinensis, são provenientes de mata seca. Há outro indício que corrobora fortemente com a hipótese de localidade equivocada. A região administrativa do Distrito Federal em que é relatado o tipo, cidade satélite de Taguatinga, possivelmente foi confundida com o município de Taguatinga, no estado de Tocantins.

5. Encyclia linearifolioides (Kraenzl.) Hoehne, Arq. Bot. Estado São Paulo 1(1): 19. 1938. Epidendrum linearifolioides Kraenzl., Kungl. Svenska Vetensk. Acad. Hand., n.s., 46 (10): 55. 1911. Tipo: PARAGUAI: S.loc., 1894, fl., Lindmann A3895 (holótipo: HBG, fotografia!).

Fig. 1f-g, 2c

Encyclia bicornuta Brade, Orquídea (Rio de Janeiro) 6(1): 16. [Setembro] 1943. Encyclia bicornuta Brade Arq. Serv. Florest. 2(1): 5. [Novembro] 1943, nom. superfl. Tipo: BRASIL. "MATTO GROSSO": S.loc., florescimento em cultivo X.1938, fl., Inspetoria Agrícola Federal da VIII Região s.n. (holótipo: RB!).

Encyclia microxanthina Fowlie, Orchid Digest 55(2): 90. 1991. Tipo. PARAGUAI. Sem local específico, floração em cultivo no L.A. Arboretum, 20.X.1990, fl., s.leg., (holótipo: UC, não localizado; lectótipo, aqui designado: fotografia publicada à direita na parte inferior em Fowlie (1991, p. 90)).
Epífita ou rupícola. Raiz 0,1-0,3 cm diâm. Rizoma inconspícuo. Pseudobulbo ovóide, roxo, $1,5-3 \times 1-1,5 \mathrm{~cm}$. Folhas 1-2(-3), lineares, planas, verdes, coriáceas, $8-25 \times 0,4-0,5 \mathrm{~cm}$. Inflorescência simples ou duplo racemosa, 3-25 flores, $11-18 \mathrm{~cm}$; pedúnculo $6-7 \mathrm{~cm}$; raque, 4-13 $\mathrm{cm}$. Flor com ovário pedicelado verde, $1,5-1,8 \mathrm{~cm}$. Sépalas lanceoladas, amarela, 1,4-1,7 ×0,3 cm. Pétalas espatuladas, amarela, 1,4-1,6 × 0,2 cm. Labelo, 1,3-1,5 × 1-1,2 cm; lobos laterais ovados, bege, $0,9-1,1 \times 0,3-0,5 \mathrm{~cm}$; lobo medial orbicular, ápice arredondado, bege, 0,5-0,6 cm diâm.; calo com ápice truncado, $0,5-0,2 \mathrm{~cm}$. Coluna sem asas, $0,7-1 \times 0,2-0,3 \mathrm{~cm}$; antera marrom escuro. Cápsula verrucosa, 2,7-3,1 ×0,9-1,6 cm.

Material selecionado: BRASIL. DISTRITO FEDERAL: Chapada da Contagem, 19.X.2005, fl., A.H. Salles et al. 3815 (HEPH). Fercal, 12.X.1992, fl., L.B. Bianchetti \& J.A.N. Batista (CEN 26615). GOIÁS: Campinaçu, estrada de Palmeira para Campinaçu, 10.X.1995, fl., B.M.T. Walter et al. 2812 (CEN). Cavalcante, rio Santo Antônio, 29.X.2007, fl., G. Pereira-Silva \& E.S. Guarino 6470 (CEN). Goiânia, 23.XI.1964, fl., E.P. Heringer 9955 (UB). Goiás Velho, 5.I.1973, fl., M. Lenig 532 (HB). Iporá, Fazenda Lage, 11.X.2008, fl., T.E.C. Meneguzzo et al. 21 (UB). Minaçu, usina Serra da Mesa, 1.XII.1998, fl., M.F. Simon 86 (UB). Niquelândia, dolina ao norte da GO-237, 7.X.2007, fl., B.M.T. Walter et al. 2033 (CEN); Macedo, 20.X.1996, fl., M.L. Fonseca et al. 1249 (IBGE). Nova Roma, estrada Ourominas-Nova Roma, 12,5km de Ourominas, 3.XII.2003, B.R. Silva et al. 1211 (RB, UB). Planaltina, XI.2008, fl., T.E.C. Meneguzzo \& L.C. Santos 26 (UB). TOCANTINS: Aguiarnópolis, canteiro de obras da AHE Estreito, 22.X.2005, fl., G.P. Silva et al. 10277 (CEN). Conceição do Tocantins, a margem do córrego Teleste, 12.I.2003, fr., N.A. Curcino 33 (HTO). Dianópolis, perto da gruta, 29.IX.2003, fl., T.B. Cavalcanti et al. 3349 (CEN). Goiatins, aldeia Pedra Branca, 15.X.2000, fl., A.A. Santos et al. 800 (CEN). Lageado, 29.X.1998, fl., G.F. Árbocz 6258 (HTO, IBGE). Palmas, serra do Lajeado, fazenda Alta Floresta, 25.X.1993, fl., E. Santos 551 (HTO). Paranã, fazenda Petrolina, 14.IX.2003, fl., A.C. Cervilha et al. 3608 (CEN). Porto Nacional, margem direita do rio Tocantins, 25.X.1993, fl., E. Santos 236 (HTO).

Material adicional examinado: BRASIL. MINAS GERAIS: Campina Verde, Fazenda S.J. do Lajeado, 27.X.2003, fl., J.F. Santos 5866 (CEN).

Espécie com distribuição no Paraguai, Bolívia e Brasil. No Brasil é registrada nos Estados de Tocantins, Mato Grosso, Goiás, Distrito Federal e Minas Gerais. Ocorre em abundância em grandes populações, no bioma Cerrado, em mata seca. Floresce no final do período seco e início do chuvoso. 
Foram registrados os forófitos hospedando os seguintes espécimens: Campomanesia eugenioides (Camb.) Legr. (Myrtaceae); sobre Cereus sp. (Cactaceae); Ficus elliotiana S.Moore (Moraceae); Hyptidendrum canum (Pohl ex Benth.) Harley (Lamiaceae); Ficus pertusa L.f. (Moraceae); Tabebuia sp. (Bignoniaceae) e Spondias sp. (Anacardiaceae).

Diferencia-se das demais espécies por apresentar pétalas e sépalas amarelas, labelo bege, com coluna sem asas e antera marrom escura.

Após buscas ao holótipo de E. microxanthina, que estaria depositado no herbário UC pela indicação no protólogo e também por informação fornecida pelo curador do herbário, não foi possível localizá-lo. Withner (2000) também indica que não o encontrou. Por esse motivo o lectótipo baseado na fotografia da flor dissecada é aqui proposto.

Os sinônimos foram aparentemente propostos pela primeira vez por Castro Neto \& Campacci (2000), apesar dos mesmos não apresentarem designação explícita como recomendada pelo artigo 50A.1 (McNeil et al. 2006) e aqui foram revisados.

6. Encyclia osmantha (Barb.Rodr.) Schltr., Orchideen (Schlechter): 210. 1914. Epidendrum osmanthum Barb.Rodr., Gen. Sp. Orchid. 2: 134. 1882. Tipo: BRASIL. "Hab. croîssant par touffes sur les arbres des forêsts pres de la Casa de Pedra, à S. José d'El-Rey, Minas Geraes. Fleurit em Septembre", s.d., J. Barbosa Rodrigues s.n. (perdido); lectótipo designado por Meneguzzo et al. (2010): AMES, ilustração original de J. Barbosa Rodrigues que seria publicada em Iconographie des Orchidées du Brésil 4: t. 14b, e reproduzida por Sprunger et al. (1996, p. 277, t. 14B).

Fig. 1h, 2d

Encyclia lutzenbergerii L.C.Menezes, Bol. CAOB 3(1): 7. 1990. Encyclia lutzenbergerii L.C.Menezes, Orchid Digest 55(1): 5. 1991, nom. superfl. Tipo: BRASIL. DISTRITO FEDERAL: Brasília, florescimento em cultivo VII.1990, fl., Z.J.G. Miranda sub L.C. Menezes UB2 (holótipo: UB!).

Encyclia lutzenbergerii var. major L.C.Menezes, Orchid Digest 56(1): 20. 1992. Tipo: BRASIL. BAHIA: Vitória da Conquista, estéril, L.C. Menezes UB20 (holótipo: UB!; epítipo, aqui designado: fotografia publicada à direita na parte inferior em Menezes (1992a, p. 21)).

[Encyclia lutzenbergerii var. Minas Geraisensis L.C.Menezes ex Fowlie \& Duveen, contracapa da reimpressão de Fowlie \& Duveen (1992), nom. nud.]
Epífita. Raiz 0,1-0,3 cm diâm. Rizoma $0,5-2 \times 0,5-0,8 \mathrm{~cm}$. Pseudobulbo estreito-ovóide, verde a roxo, $5-11 \times 1-1,5 \mathrm{~cm}$. Folha $2-3$, linearlanceolada, plana, verde a roxa, coriácea, $10-45 \times$ $1-2,5 \mathrm{~cm}$. Inflorescência duplo recemosa, 7-25 flores, 45-95 cm; pedúnculo $26-50 \mathrm{~cm}$; raque $20-40 \mathrm{~cm}$. Flor com ovário pedicelado verde, $2-2,5$ $\mathrm{cm}$. Sépala lanceolada, verde a marrom, 1,7-2,2 $\times$ $0,5-0,6 \mathrm{~cm}$. Pétala espatulada, ápice arredondado a ligeiramente apiculado, verde a marrom, 1,7-2,1 $\times 0,5-0,7 \mathrm{~cm}$. Labelo $1,7-2,2 \times 1,5-1,8 \mathrm{~cm}$; lobos laterais elípticos, ápice arredondado, bege, $0,8-1,3 \times 0,4-0,7 \mathrm{~cm}$; lobo medial transversoelíptico, ápice freqüentemente emarginado, bege, centro rosa a bege, $0,8-1,5 \times 0,8-1,1 \mathrm{~cm}$; calo cimbiforme, ápice inteiro, $0,5-0,6 \times 0,2-0,3 \mathrm{~cm}$. Coluna com asas, bege a verde, $1-1,2 \times 0,3-0,4$ $\mathrm{cm}$; antera amarela. Cápsula verrucosa, marrom, $3,5-4 \times 0,7 \mathrm{~cm}$.

Material selecionado: BRASIL. DISTRITO FEDERAL: Córrego Vicente Pires, 21.VIII.1990, fl., I. Valente 24 (HEPH). Estação Ecológica do Jardim Botânico de Brasília, córrego Cabeça de Veado, próximo ao T6, 28.VIII.1996, fl., M.G. Nóbrega 504 (HEPH). Fazenda Água Limpa, córrego Olho d'Água da Onça, 18.VII.1989, fl., M. Pereira Neto et al. 361 (IBGE). Fazenda Sucupira, 23.VIII.2000, fl., B.M.T. Walter et al. 4477 (CEN). Horto do Guará, 7.VII.1961, fl., E.P. Heringer 8453 (HB, UB). Jardim Botânico de Brasília, córrego Cabeça de Veado, 17.VIII.1999, fr., M.G. Nobrega 986 (HEPH, UB). Parque do Gama, 6.V.1963, fr., Pires et al. 9639 (HB). Parque Nacional de Brasília, 20.V.1962. fl., E P. Heringer 9691 (HB). Reserva Ecológica do IBGE, córrego Taquara, 8.XI.1989, fl., M.L. Azevedo \& E.C. Lopes 405 (IBGE). Setor de Mansões Lago Norte, córrego Tamanduá, 20.X.1991, fl., L.B. Bianchetti \& J.A.N. Batista 1178 (CEN). Taguatinga, Fazenda Pequeno Saltador, 25.VIII.1992, fl., J.A.N. Batista 207 (CEN). GOIÁS: Formosa, 1.IX.2004, fl., A.A. Santos \& J.B. Pereira 2086 (CEN). Gama, entre Gama e Rio Corumbá, 6.X.1963, fl., J.M. Pires 5117 (UB). Parque Nacional do Tocantins, entre Morro das Antas e Alto Paraíso, IX.1967, fl., de Haas et al. 402 (HB). Pirenópolis, 29.VIII.2009, fl., C. Proença \& S.A. Harris 3623 (UB). Sítio d'Abadia, 18.IX.2009, fr., A.K. Peres Júnior et al. 12 (UB).

Material adicional examinado: BRASIL. MINAS GERAIS: Delfinópolis, Parque Nacional da Serra da Canastra, X.2002, fl., R.A. Pacheco et al. 249 (UB).

Espécie dispersa em Goiás, Distrito Federal, Minas Gerais e Bahia. Ocorrente no Cerrado em matas ciliares e de galeria. Floresce predominantemente no final do período seco e início do chuvoso, agosto-novembro. 
Foram registrados espécimes crescendo nos forófitos Magnolia ovata (A.St.-Hil) Spreng. (Magnoliaceae) e Belangera sp. (Cunoniaceae).

Para verificação dos caracteres que distinguem Encyclia osmantha de E. argentinensis e $E$. chapadensis ver comentários sob estas.

A foto do perianto distendido apresentada no protólogo de Encyclia lutzenbergerii var. major L.C.Menezes é aqui designada como epítipo, devido ao fato do holótipo não apresentar flores. $\mathrm{O}$ nome "Encyclia osmanta var. Minas Geraisensis" é aqui considerado nome nú por não cumprir as exigências previstas no artigo 32.1 (McNeil et al. 2006); entretanto, o exemplar ao qual este nome está associado se enquadra perfeitamente no conceito de E. osmantha e, portanto, é aqui sinonimizado.

\section{Espécies e conceitos excluídos}

Pabst \& Dungs (1975), Castro Neto \& Campacci (2000), Campacci (2003), Batista \& Bianchetti (2003) e Barros et al. (2010) citam para o Distrito Federal e Estados de Goiás e Tocantins Encyclia chloroleuca (Hook.) Neumann, E. conchaechila (Barb.Rodr.) Porto \& Brade, E. gallopavina (Rchb.f.) Porto \& Brade, E. longifolia (Barb.Rodr.) Schltr., Encyclia $\times$ alcardoi V.P.Castro \& Chiron, E. euosma (Rchb.f.) Porto \& Brade, E. odoratissima (Lindl.) Schltr., E. flava (Lindl.) Porto \& Brade, E. tripartita (Vell.) Hoehne, E. ensiformis (Vell.) Hoehne e E. amicta (Rchb.f.) Porto \& Brade. Tais espécies não possuem ocorrência confirmada para as unidades federativas em questão, por não terem sido mencionados e/ou encontrados materiais testemunho depositados em herbários, e não terem sido encontradas em expedições a campo realizadas pelos autores.

Segundo nossas observações, os espécimes tratados pelos autores supramencionados como Encyclia flava, E. conchaechila, E. tripartita e E. amicta, na verdade, representam, todos, diferentes nomes do que são aqui aceitas como Encyclia linearifolioides (Kraenzl.) Hoehne. A má aplicação desses nomes é justificada pelo fato de $E$. flava ser reconhecida atualmente como sinônimo de $E$. patens Hook., já E. conchaechila como espécie independente e nativa da Amazônia brasileira e venezuelana (Carnevali et al. 2003; Castro Neto 2008; Dalström 2006), portanto, duas entidades que não ocorrem na presente área de estudo. A mesma justificativa vale para E. amicta e E. tripartita, que apesar de possuírem identidade duvidosa, são aceitas como entidades independentes por alguns autores (Duntersville \& Garay 1959; Castro Neto $\&$ Chiron 2002a, respectivamente).

Outro táxon excluído desse estudo é Encyclia $\times$ alcardoi. Apesar de ser necessário saber, no mínimo, somente um dos pais para o reconhecimento de um híbrido (artigo H.3.2, McNeil et al. 2006), a informação constante no protólogo é ambígua a ponto de ser inconclusiva. Esse táxon foi descrito como híbrido resultado do cruzamento natural entre E. argentinensis e E. flava. Segundo o protólogo (Castro Neto \& Chiron 2002b), o único espécime encontrado possui flores mais semelhantes a $E$. argentinensis e a parte vegetativa a $E$. flava. $\mathrm{O}$ conceito empregado no protólogo para $E$. flava foi o de Castro Neto \& Chiron (2002a). No nosso entendimento o conceito de E. flava de Castro Neto \& Chiron (2002a,b) é incorreto, e nossa hipótese é corroborada por Dalström (2006) e Castro Neto (2008). Castro Neto \& Chiron (2002b) utilizam o binômio E. flava, que é na verdade sinônimo de E. patens (supracitado), para nomear duas espécies distintas: E. linearifolioides e E. conchaechila. Os autores ainda ilustram no protólogo intercambiavelmente como E. flava, ora o que reconhecemos como E. linearifolioides (Castro Neto \& Chiron 2002b, p. 152, 155 e 157) e ora como E. conchaechila (ibidem, p. 151). Apesar de ser confirmada a existência de $E$. linearifolioides para a localidade tipo (Porto Nacional, estado de Tocantins; ver lista de materiais examinados) não foi confirmada nem $E$. conchaechila e nem $E$. argentinensis, o que resolveria a questão de quais são os pais do híbrido. O holótipo depositado no herbário SP consiste em fragmentos de uma flor. Mesmo o exame das ilustrações e descrições constantes no protólogo não foi possível chegar a uma boa conclusão sobre o híbrido. Portanto, este táxon é considerado como excluído devido ao tipo nomenclatural pouco esclarecedor, confirmação dos pais e sua simpatria, sincronismo de floração de forma a possibilitar o cruzamento na natureza para identificação e clarificação da identidade do híbrido.

Encyclia longifolia (Barb.Rodr.) Schltr., atualmente conhecida como E. oncidioides (Lindl.) Schltr., tem sua ocorrência descartada, uma vez que se trata de espécie da região litorânea do Brasil adentrando em algumas porções do continente, como a Chapada Diamantina, Bahia (Pabst \& Dungs 1975; Toscano de Brito \& Cribb 2005). Do mesmo modo, até onde averiguamos Encyclia 
gallopavina (Rchb.f.) Porto \& Brade é restrita ao Rio de Janeiro, Espírito Santo e Minas Gerais.

Por outro lado, E. chloroleuca, E. randii (Barb.Rodr.) Porto \& Brade e E. conchaechila (essa última tratada no conceito original de Barbosa Rodrigues (1877), supracitado) poderiam ocorrer no norte e oeste do Tocantins, entretanto, foram excluídas por não possuírem materiais testemunho que comprovassem ocorrência na área em estudo.

O trabalho de Castro Neto \& Chiron (2005) traz esclarecimentos quanto ao entendimento atual de Encyclia euosma (Rchb.f.) Porto \& Brade, representando, entre outras características, uma espécie tipicamente epífita, ocorrente na Serra do Mar e Serra dos Órgãos (bioma Floresta Atlântica), no sul e sudeste brasileiro. Entretanto, G.F.J. Pabst aplicava outro conceito morfológico e ecológico para E. euosma. A comprovação dessa afirmação é justificada pelo exame dos materiais identificados e observações, em forma de notas, presentes nos arquivos pessoais de Pabst, conservados pelo Herbarium Bradeanum. O conceito de E. euosma se referia a uma planta rupícola com porte compacto, pseudobulbos quase esféricos, longa inflorescência pauciflora e lobos do labelo proporcionalmente grandes para o gênero. Esse conceito foi, de alguma forma, registrado em sua obra (Pabst \& Dungs 1975, 1977) com ilustrações de flores dissecadas (Pabst \& Dungs 1975, p. 298, fig. 654), e como ocorrente nos Estados Pará, Mato Grosso e Goiás (bioma Amazônico e Cerrado). Como obra fundamental de referência, muitos pesquisadores, ao efetuarem levantamentos florísticos, perpetuaram o conceito de Pabst \& Dungs (1975) para as plantas com aquelas características encontradas (e.g. Munhoz \& Proença 1998 e Mendonça et al. 2008). De acordo com exame de espécimes ocorrentes na área do presente estudo, constatamos que se tratava de E. chapadensis. Concluímos também que os espécimes procedentes do Pará, em específico da Serra do Cachimbo, são na verdade E. caximboensis L.C.Menezes. Nenhum exemplar consultado correspondia a E. euosma, segundo o protólogo e o tipo nomenclatural e por esse motivo foi excluída, como ocorrente, da área do presente estudo.

Da mesma maneira que para a espécie anterior, autores contemporâneos como Withner (2000) e Romanini \& Barros (2007) trazem esclarecimentos fundamentais para o melhor entendimento de Encyclia odoratissima (Lindl.) Schltr. Desse modo entende-se que esta é sinônimo de E. patens Hook. e ocorre na Serra do Mar e
Serra dos Órgãos (bioma Floresta Atlântica). De acordo com exame de materiais ocorrentes na área do presente estudo e identificados incorretamente como E. odoratissima, e também citados por Brasil (2004), Mendonça et al. (2000) e Pereira et al. (1993), constatamos que se referem a $E$. osmantha. Por esse motivo, E. odoratissima foi excluída, como ocorrente, da área do presente estudo. Pabst \& Dungs (1975) também citam E. ensiformis como sendo na verdade espécimes de E. osmantha.

Existem três espécimes identificados como tipos nomenclaturais sob os nomes de "Encyclia reflexa J.González" e "E. delicata L.C.Menezes" respectivamente: L.C. Menezes UB81, proveniente da Ilha do Bananal, Tocantins, no herbário UB, e L.C. Menezes UB71, de Formosa, Goiás, nos herbários G e UB. Como ocorrentes na área de estudo, essas espécies deveriam ser citadas. Entretanto, por não terem sido publicados. A inexistência de flores nos espécimes e também o segundo apresentar mistura de materiais diferentes, torna impossível a identificação desses espécimes e justificam a exclusão do presente trabalho.

\section{Conclusão e Considerações Finais}

Todos os táxons foram encontrados somente no bioma Cerrado. Considera-se que o Distrito Federal e Goiás são bem representativos quanto à diversidade e número de espécies. O segundo estado apresenta espécies raras para o gênero, $E$. cyperifolia e E. chapadensis. O estado do Tocantins carece de coletas como um todo, sendo a espécie melhor amostrada, E. linearifolioides, muito comum no bioma Cerrado.

Ao total, quarenta e dois nomes foram revisados. Duas novas sinonimizações, quatro lectótipos e dois epítipos são propostos. Um nome é indicado como inválido, quatro como supérfluos e quatro como nulos. Treze nomes, incluídos em listagens anteriores para a área em questão, foram excluídos do tratamento por falta de material testemunho ou outro tipo de evidência e três são registrados como de possível ocorrência.

Este trabalho tem sua importância elevada especialmente no que diz respeito ao número real de táxons ocorrentes em Goiás, Tocantins e Distrito Federal; pelo esclarecimento do estado taxonômico de muitos nomes, enquadramento de muitos outros segundo as regras do Código Internacional de Nomenclatura Botânica, além de várias tipificações e também como contribuição inicial para a revisão do gênero Encyclia. 


\section{Agradecimentos}

Agradecemos aos herbários consultados pelas informações, acesso e empréstimo das coleções; C. van den Berg pelos esclarecimentos e discussões a respeito do Código; C.S. Caires pela confecção dos mapas; L. Versieux por fotografias de tipos; S.A. Freitas e sua família pelo apoio a campo em Iporá, Goiás; ao Clube da Encyclia de Brasília, A.K. Peres Júnior, A.D. Santana, A. Marques, B.P. Faria, J. Serafim Sobrinho e L.C. Santos pelas calorosas discussões taxonômicas, acesso aos seus orquidários, troca de bibliografia e material fotográfico; L.C. Menezes, V.P. Castro Neto e D.L. Szlachetko por algumas das referências aqui citadas e Z.J.G. Miranda pelas fichas de flores de espécimes. Este artigo é parte do projeto de iniciação científica do primeiro autor, o qual agradece o Conselho Nacional de Desenvolvimento Científico e Tecnológico pela bolsa concedida.

\section{Referências}

Ames, O.; Hubbard, F.T. \& Schweinfurth, C. 1936. The genus Epidendrum in the United States and Middle America. Cambridge Press, Cambridge. 233p.

Barbosa Rodrigues, J. 1877. Genera et species orchidearum novarum. Vol. 1. C. \& H. Fleiuss, Rio de Janeiro. 215p.

Barbosa Rodrigues, J. 1882. Genera et species orchidearum novarum. Vol. 2. Typographia Nacional, Rio de Janeiro. 305p.

Barbosa Rodrigues, J. 1891. Genera et species orchidearum novarum. 2 ed. Vellosia 1: 115-133.

Barros, F.; Vinhos, F.; Rodrigues, V.T.; Barberena, F.F.V.A. \& Fraga, C.N. 2010. Orchidaceae In: Forzza, RC. et al. (eds.). Lista de espécies da flora do Brasil. Jardim Botânico do Rio de Janeiro. Disponível em <http://floradobrasil.jbrj.gov. br/2010/FB011518>. Acesso em 20 Out 2010.

Batista, J.A.N. \& Bianchetti, L.B. 2003. Lista atualizada das Orchidaceae do Distrito Federal. Acta Botanica Brasilica 14: 183-201.

Brasil. 2004. Reserva Ecológica do IBGE; Ambiente e Plantas Vasculares. Instituto Brasileiro de Geografia e Estatística, Rio de Janeiro. 70p.

Campacci, M.A. 2003. Encyclia. Coletânea de Orquídeas Brasileiras 1: 1-32.

Carnevali, G.; Ramírez-Morillo, I.M.; Romero-González, G.A.; Vargas, C.A. \& Foldats, E. 2003. Orchidaceae. In: Berry, P.E.; Yatskievych, K. \& Holts, B.K. (eds.). Flora of the Venezuelan Guayana. Vol. 7. Missouri Botanical Garden, Saint Louis. Pp. 200-618.

Castro Neto, V.P. 1998a. Contribuição ao estudo das Encyclias brasileiras; parte 1. Orquidário 12: 43-50.
Castro Neto, V.P. 1998b. Contribuição ao estudo das Encyclias brasileiras; conclusão. Orquidário 12: 67-71.

Castro Neto, V.P. (ed.). 2006. Icones Orchidacearum Brasiliensis 2: t. 101-200.

Castro Neto, V.P. 2008. Encyclia flava e sua intrincada determinação. Boletim CAOB 71: 35-37.

Castro Neto, V.P. \& Campacci, M.A. 1996. Nova espécie de Encyclia do estado do Tocantins. Orquidário 10: 14-15.

Castro Neto, V.P. \& Campacci, M.A. (eds.). 2000. Icones Orchidacearum Brasiliensis 1: t. 1-101.

Castro Neto, V.P. \& Chiron, G.R. 2002a. Encyclia flava (Lindley) Porto \& Brade. Richardiana 2: 164-171.

Castro Neto, V.P. \& Chiron, G.R. 2002b. Un nouvel Encyclia hybride de la region centrale du Brésil. Richardiana 2: 150-157.

Castro Neto, V.P. \& Chiron, G.R. 2005. Contribution à la connaissance des orchidées du Brésil VIII; Encyclia euosma (Reichenbach.f.) Porto \& Brade et Encyclia ionosma (Lindley) Porto \& Brade. Richardiana 5: 71-78.

Christenson, E.A. \& Carnevali, I.R. 1988. Revisión del genero Encyclia para Venezuela. Boletim del comite de orquideología 23: 13-87.

Cogniaux, A.C. 1898. Orchidaceae: Epidendrum. In: Martius, C.F.P.; Eicher, A.G. \& Urban, I. (eds.). Flora brasiliensis. Vol. 3, Pars 5. Typographia Regia, Munich. Pp. 29-185.

Dalström, S. 2006. Encyclia flava and its multiple identities. Selbyana 27: 96-100.

Dressler, R.L. 1961. A reconsideration of Encyclia. Brittonia 13: 253-266.

Dressler, R.L. 1990. The orchids: natural history and classification. Harvard University Press, Cambridge. $332 \mathrm{p}$.

Dressler, R.L. \& Pollard, G.E. 1974. The genus Encyclia in Mexico. Asociación Mexicana de Orquidologia, Ciudad de México. 151p.

Duntersville, G.C.K. \& Garay, L.A. 1959. Venezuelan orchids illustrated. Vol. 1. Andre Deutsch, Amsterdam. 448p.

Fowlie, J.A. 1991. An inconspicuously flowered new species of Encyclia from Paraguay, Encyclia microxanthina Fowl., sp. nov. Orchid Digest 55: 90-91.

Fowlie, J.A. \& Duveen, D. 1992. A contribution to an understanding of the genus Encyclia as it occurs in the Brazilian shield and its river tributaries. Orchid Digest 56: 171-206.

Gonzalez, J.R. 1992. Encyclia perazolliana Gonzalez, sp. nov. Boletim CAOB 4: 21-23.

Higgins, W.E. 1997. A reconsideration of the genus Prosthechea. Phytologia 82: 370-383. 
Hoehne, F.C. 1952. Lista preliminar das espécies do gênero Encyclia Hooker para controle. Arquivos de Botânica do Estado de São Paulo 2: 147-156.

Hooker, W.L. 1828. Encyclia viridiflora. Botanical Magazine 55: t. 2831.

Lindley, J. 1853. Epidendrum. In: Lindley, J. (ed.). Folia Orchidacea. J. Matthews, London. 429p.

McNeil, J.; Barrie, F.R.; Burdet, H.M.; Bemoulin, V.; Hawksworth, D.L.; Marhold, K.; Nicolson, D.H.; Prado, J.; Silva, P.C.; Skog, J.E.; Wiersema, J.H. \& Turland, N.J. (eds.). 2006. International Code of Botanical Nomenclature; Vienna Code. Regnum Vegetabile 146: 1-568.

Mendonça, R.C., Felfili, J.M. \& Silva, J.C.S. 2000. Diversidade e composição florística das áreas nucleares da Reserva da Biosfera do Cerrado - Fase I. In: Schenkel, C.S. \& Brummer, B.M. (coords.). Vegetação do Distrito Federal; tempo e espaço. UNESCO, Brasília. Pp. 31-34, Ap. 3.

Mendonça, R.C.; Felfili, J.M.; Walter, B.M.T.; Silva Júnior, M.C.; Rezende, A.V.; Filgueiras, T.S.; Nogueira, P.E. \& Fagg, C.W. 2008. Flora vascular do bioma cerrado; checklist com 12.356 espécies. In: Sano, S.M.; Almeira, S.P. \& Ribeiro, J.F. (eds.). Cerrado; ecologia e flora. Vol. 2. Embrapa Informação Tecnológica, Brasília. Pp. 421-1279.

Meneguzzo, T.E.C.; Bianchetti, L.B. \& Proença, C.E.B. 2010. Typifications of Brazilian names of the genus Encyclia (Orchidaceae). Neodiversity 5: 18-22.

Menezes, L.C. 1991a. Encyclia goyazensis L. C. Men., sp. nov. et Encyclia schmidtii L. C. Men., sp. nov. Orchid Digest 55: 92-94.

Menezes, L.C. 1991b. Two new Encyclia species from the Planalto of Brazil: Encyclia gonzalezii, L. C. Men., n. sp. et Encyclia lutzenbergerii, L. C. Men., n. sp. Orchid Digest 55: 24-27.

Menezes, L.C. 1992a. Variations in Encyclia lutzenbergerii L. C. Men. and its affinity with Encyclia osmantha (Barb.Rodr.) Porto \& Brade. Orchid Digest 56: 20-21.

Menezes, L.C. 1992b. Two new Brazilian Encyclias from Espirito Santo in Brazil, Encyclia andrichii and Encyclia pedra-azulensis. Orchid Digest 56: 148-150.

Munhoz, C.B.R. \& Proença, C.E.B. 1998. Composição florística do município de Alto Paraíso de Goiás na Chapada dos Veadeiros. Boletim do Herbário Ezechias Paulo Heringer 3: 102-150.

Pabst, G.F.J. \& Dungs, F. 1975. Orchidaceae Brasiliensis. Vol. 1. Brücke-Verlag Schersow, Hildescheim. 408p.

Pabst, G.F.J. \& Dungs, F. 1977. Orchidaceae Brasiliensis. Vol. 2. Brücke-Verlag Schersow, Hildescheim. 418p.

Pereira, B.S.S., Silva, M.A. \& Mendonça, R.C. 1993. Reserva Ecológica do IBGE, Brasília (DF); Lista das plantas vasculares. Instituto Brasileiro de Geografia e Estatística, Rio de Janeiro. 43p.
Primão, A. 1997. Estudos sistemáticos: o gênero Encyclia na região de Casa Branca - SP. Boletim CAOB 27: $20-31$.

Ribeiro, J.F. \& Walter, B.M.T. 2008. As principais fitofisionomias do bioma Cerrado. In: Sano, S.M., Almenda, S.P. \& Ribeiro, J.F. (eds.). Cerrado; ecologia e flora. Vol. 1. Embrapa Informação Tecnológica, Brasília. Pp. 151-212.

Romanini, R.P. \& Barros, F. 2007. Orchidaceae. In: Melo, M.M.F.R.; Barros, F.; Chiea, S.A.C.; Kirizawa, M.; Jung-Mendaçolli, S.L. \& Wanderley, M.G.L. (eds.). Flora fanerogâmica da Ilha do Cardoso. Vol. 12. Instituto de Botânica, São Paulo. Pp. 29-275.

Sauleda, R.P. \& Adams, R.M. 1983. The genus Encyclia Hook. (Orchidaceae) in the Bahama archipelago. Rhodora 85: 127-174.

Schlechter, [F.R.]R. 1914. Encyclia. In: Die Orchideen; ihre Beschreibung, Kultur und Züchtung. Verlagsbuchhandlung Paul Parey, Berlin. Pp. 207-212.

Silva, A.M.; Assad, E.D. \& Evangelista, B.A. 2008. Caracterização climática do bioma Cerrado. In: Sano, S.M.; Almeida, S.P. \& Ribeiro, J.F. (ed.). Cerrado: ecologia e flora. Vol. 1. Empresa Brasileira de Agricultura e Pecuária - Informação Tecnológica, Brasília. Pp. 69-88.

Spegazzini, C. 1916. Algunas orquidáceas argentinas. Anales Museu Nacional de Historia Natural de Buenos Aires 28: 131-140.

Sprunger, S.; Cribb, P. \& Toscano de Brito, A. 1996. Iconographie des Orchidées du Brésil. Vol. 1. Friedrich Reinhardt, Basle. 540 pp.

Stern, W.T. 2004. Botanical Latin. Timber Press, Portland. $4^{\text {th }}$ ed. 546 pp.

Szlachetko, D.L.; Margońska, H.B. 2002. Gymnostemia Orchidalium II. Acta Botanica Fennica 173: 1-275.

Thiers, B. (continuamente atualizado). 2010. Index Herbariorum. Disponível em $<$ http://sweetgum. nybg.org/ih/>. Acesso em 20 Out 2010.

Toscano de Brito, A.L.V.; Cribb, P. 2005. Orquídeas da Chapada Diamantina. Nova Fronteira, Rio de Janeiro. 399p.

Weberling, F. 1989. Morphology of flowers and inflorescences. Cambridge University Press, Cambridge. $423 p$.

Withner, C.L. 1996. The Cattleyas and their relatives: the Bahamian and Caribbean species. Vol. 4. Timber Press, Portland. 198p.

Withner, C.L. 1998. The Cattleyas and their relatives: Brassavola, Encyclia and other genera of México and Central America. Vol. 5. Timber Press, Portland. $242 p$.

Withner, C.L. 2000. The Cattleyas and their relatives: the South American Encyclia species. Vol. 6. Timber Press, Portland. 222p. 
van den Berg, C.; Fernández-Concha, G.C.; Pridgeon, A.M.; Veitch, N.C. \& Grayer, R.J. 2005. Encyclia. In: Pridgeon, A.M.; Cribb, P.J.; Chase, M.W. \& Rasmussen, F.N. (eds.). Genera Orchidacearum; Epidendroideae, part two. Vol 4. Oxford University Press, New York. Pp. 232-236. van den Berg, C.; Higgins, W.E.; Dressler, R.L.; Whitten, W.M.; Soto-Arenas, M.A. \& Chase, M.W. 2009. A phylogenetic study of Laeliinae (Orchidaceae) based on combined nuclear and plastid DNA sequences. Annals of Botany 104: 417-430. 